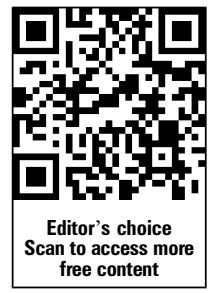

'Manchester Medical School, University of Manchester, Manchester, UK ${ }^{2}$ Lancashire Teaching Hospitals NHS Foundation Trust, Preston, UK

\section{Correspondence to} Gareth Jones, gareth.jones-5@student. manchester.ac.uk

Accepted 16 April 2014

\title{
Successful use of stellate ganglion block and a new centrally acting analgesic with dual mode of action in a resistant temporomandibular joint pain
}

\author{
Gareth Peter Jones, ${ }^{1}$ Shiva Shankar Tripathi ${ }^{2}$
}

\section{SUMMARY}

Stellate ganglion blocks have been shown to provide effective pain relief in a number of different conditions involving the upper body. This was demonstrated in a 65-year-old woman who had experienced severe debilitating pain in her left temporomandibular joint (TMJ) and the surrounding area of her face for over 10 years. The pain was unresponsive to indomethacin, carbamazepine, sodium valproate, gabapentin, lithium, melatonin and amitriptyline. She had also had four surgical procedures to the TMJ without success. The pain was partially responsive to Syndol tablets and pregabalin, although the use of pregabalin was limited by its adverse effects. The patient underwent 13 ultrasound guided stellate ganglion blocks over a 24-month period which demonstrated $90 \%$ pain relief for up to 10 weeks. Pulsed radio frequency lesioning showed no benefit over stellate ganglion block. More recently, tapentadol was found to be effective and this replaced the stellate ganglion blocks.

\section{BACKGROUND}

Block of the stellate ganglion has been used for the relief of pain syndromes such as complex regional pain syndrome, ${ }^{12}$ as well as vascular insufficiency syndromes such as Raynaud's phenomenon. ${ }^{3}$ However, it has also been shown to have application in some other conditions such as post-traumatic stress disorder, ${ }^{4}$ anxiety ${ }^{5}$ and in perimenopausal women to help control hot flushes. ${ }^{6}$

This case demonstrates the successful use of stellate ganglion block in resistant temporomandibular joint (TMJ) pain which had been present for over 10 years. It also demonstrates that a new dual action analgesic, tapentadol, was able to control the pain, removing the need for multiple stellate ganglion blocks.

\section{CASE PRESENTATION}

The patient was a 65 -year-old woman who worked approximately $12 \mathrm{~h}$ a week as a part-time cleaner. She was referred to the pain team at the Royal Preston Hospital with a history of left TMJ pain. There was no history of pain in the right side. This pain had been present for approximately 10 years and was associated with migraines which she had been having since the age of 10 . The pain was described as intense and was spontaneously triggered by cold air, for example, wind, fans and air conditioning units. It could also be triggered by what was described as a 'stuffy head' during a cold.
When triggered, the pain would last between 12 and $24 \mathrm{~h}$ with an intensity of ' $11 / 10$ '. The patient found that Syndol tablets (paracetamol $450 \mathrm{mg}$, codeine phosphate $10 \mathrm{mg}$, doxylamine succinate $5 \mathrm{mg}$ and caffeine $30 \mathrm{mg}$ ), ${ }^{7}$ in addition to warmth, steam inhalation and deep heat rub, helped the pain.

Prior to referral to the pain team, the patient had already undergone four surgical procedures to the left TMJ, and had been seen by a consultant neurologist specialising in TMJ pain. She had also tried a number of different medications for the pain, including indomethacin, carbamazepine, sodium valproate, gabapentin, lithium, melatonin, amitriptyline and pregabalin. The only medication that had been helpful apart from the Syndol was pregabalin, which offered her some relief but had to be stopped due to the side effects of weight gain and memory impairment. At presentation at the clinic, the patient was only taking Syndol and half a $25 \mathrm{mg}$ tablet of amitriptyline before sleep.

On examination there was no asymmetry of movement in the TMJ joints and no allodynia to light touch, but there was allodynia and paraesthesia to deep palpation around the left TMJ. Multiple computerised tomography and magnetic resonance scans had also shown nothing surgically correctable. As there had not been an acute nociceptive insult but there was allodynia and paraesthesia (to cold air in the history and to deep palpation in the examination), a working diagnosis of neuropathic pain around the left TMJ following multiple surgical interventions was made.

\section{TREATMENT}

Treatment posed a challenge to the pain team as many of the neuropathic pain medications had already been unsuccessful. Lignocaine plasters were prescribed but were not helpful. The patient also received an injection of steroid and local anaesthetic into the TMJ under ultrasound guidance which gave immediate but short-lasting (1 week) pain relief. Pregabalin was then reintroduced but again was associated with intolerable side effects including unsteadiness and forgetfulness.

At this point, most management strategies had been tried and it was felt that there were very few other options. However, it was decided to trial stellate ganglion block as the TMJ injection had provided short-term relief. In February 2009 a left stellate ganglion block was performed successfully 
under ultrasound guidance using $15 \mathrm{~mL}$ of $0.25 \%$ bupivacaine. On attending for a second block, the patient reported $90 \%$ pain relief in the 2 weeks following the previous block. The second block was performed and the patient again reported $90 \%$ pain relief for 3 weeks before the pain returned. As this demonstrated such great benefit, the treatment was repeated a further eight times up until October 2010, with four blocks in the first 6 months. The blocks showed similar pain relief but for an increasing period of up to 10 weeks.

Since the blocks had been very successful, pulsed radio frequency lesioning was trialled as it had the advantage of potential pain relief for up to 12 months. Following discussion with the patient about the risks and benefits of the procedure, she decided to go ahead with it. After the procedure she experienced a similar degree of pain relief but for only about 6 weeks, which was less successful than the stellate ganglion blocks. As a result, the patient had a further stellate ganglion block which again lasted for 8-10 weeks.

Due to the risks of repeated block, ketamine was trialled as an alternative but was unsuccessful. Following this, tapentadol, a new dual-acting opioid analgesic, ${ }^{8}$ was introduced at a starting dose of $50 \mathrm{mg}$ twice daily. This had a favourable effect with the patient reporting 50-70\% pain relief.

\section{OUTCOME AND FOLLOW-UP}

Following the successful introduction of tapentadol, the patient returned to the clinic for a follow-up appointment. The dose had been increased to $100 \mathrm{mg}$ twice daily and she felt $95 \%$ better and was able to tolerate air conditioning and some drafts. She felt that this was a great improvement and was much more positive about the future. Although they were highly successful, no further stellate ganglion blocks were required as tapentadol had a comparable if not better effect on her pain and did not carry the risks of stellate ganglion block. The patient also reported that she had no side effects from the tapentadol.

\section{DISCUSSION}

The stellate ganglion provides fibres to the TMJ and surrounding area, ${ }^{9}$ which could partly explain the efficacy of the block for the pain our patient was experiencing. There is very little in the literature on TMJ or facial pain, but the studies that have been published support stellate ganglion block as an effective treatment for pain in areas similar to that of our patient. ${ }^{10} 11$ However, there are potential side effects, some of which are serious, such as cardiac arrest, ${ }^{12}$ which must be considered when discussing the risks and benefits of the procedure.

Tapentadol is a combined $\mu$-opioid receptor and noradrenaline re-uptake inhibitor which has been shown to be effective in chronic and neuropathic pain. ${ }^{13-16}$ It also has a better side effect profile than other opioids. ${ }^{17}$ As a result it has been used in patients with chronic and neuropathic pain. These characteristics also made it a suitable choice for our patient who had severe, chronic neuropathic pain but had been unable to tolerate other opioids due to side effects. As shown in this case, tapentadol was highly effective and resulted in a 95\% reduction in our patient's pain while having a more acceptable side effect profile, with our patient showing no adverse effects at all.

Our case in combination with literature reports suggests that stellate ganglion block has potential benefits for patients with resistant facial pain. This case indicates that stellate ganglion block should be attempted when there is uncontrolled pain despite optimal medical therapy. However, in the case of our patient, an effective pharmacological treatment without adverse effects was found: this therapy was tapentadol, a relatively new dual action analgesic.

\section{Learning points}

- Stellate ganglion block was highly effective in this case and could be trialled in patients with similar resistant facial pain with neuropathic features.

- However, stellate ganglion block carries some risks which must be considered.

- Tapentadol may be an effective option for the relief of facial and temporomandibular joint pain, and seems to have a better side effect profile than other opioid medications.

Contributors Both authors contributed equally to this report.

Competing interests None.

Patient consent Obtained.

Provenance and peer review Not commissioned; externally peer reviewed.

\section{REFERENCES}

1 Melis M, Zawawi K, Al-Badawi E, et al. Complex regional pain syndrome in the head and neck: a review of the literature. J Orofac Pain 2002;16:93-104.

2 Yucel I, Demiraran Y, Ozturan K, et al. Complex regional pain syndrome type I: efficacy of stellate ganglion blockade. J Orthop Traumatol 2009;10:179-83.

3 Lemônica L, Trentin L. Raynaud's syndrome: two treatment techniques in comparison. Reg Anesth Pain Med 1993;18(S1):46.

4 Lipov EG, Navaie M, Brown PR, et al. Stellate ganglion block improves refractory post-traumatic stress disorder and associated memory dysfunction: a case report and systematic literature review. Mil Med 2013;178:e260-4.

5 Alino J, Kosatka D, McLean B, et al. Efficacy of stellate ganglion block in the treatment of anxiety symptoms from combat-related post-traumatic stress disorder: a case series. Mil Med 2013;178:e473-6.

6 Van Gastel P, Kallewaard JW, Van der Zanden M, et al. Stellate-ganglion block as a treatment for severe postmenopausal flushing. Climacteric 2013;16:41-7.

7 SSL_International_PLC. Syndol Caplets_PIL_eMC. Secondary Syndol Caplets_PIL -eMC 2012. http://www.mhra.gov.uk/home/groups/spcpil/documents/spcpil/ con1365399478368.pdf (accessed 30 Apr 2014).

8 Tzschentke TM, Christoph T, Kogel B, et al. (-)-(1R,2R)-3-(3-dimethylamino-1-ethyl2-methyl-propyl)-phenol hydrochloride (tapentadol $\mathrm{HCl}$ ): a novel mu-opioid receptor agonist/norepinephrine reuptake inhibitor with broad-spectrum analgesic properties. J Pharmacol Exp Ther 2007:323:265-76.

9 Uddman R, Grunditz T, Kato J, et al. Distribution and origin of nerve fibers in the rat temporomandibular joint capsule. Anat Embryol 1998;197:273-82.

10 Makharita MY, Amr YM, El-Bayoumy Y. Effect of early stellate ganglion blockade for facial pain from acute herpes zoster and incidence of postherpetic neuralgia. Pain Physician 2012;15:467-74.

11 Salvaggio I, Adducci E, Dell'Aquila L, et al. Facial pain: a possible therapy with stellate ganglion block. Pain Med 2008;9:958-62.

12 Rastogi S, Tripathi S. Cardiac arrest following stellate ganglion block performed under ultrasound guidance. Anaesthesia 2010;65:1042-2.

13 Galvez R, Schafer M, Hans G, et al. Tapentadol prolonged release versus strong opioids for severe, chronic low back pain: results of an open-label, phase $3 \mathrm{~b}$ study. Adv Ther 2013;30:229-59.

14 Christoph T, De Vry J, Tzschentke TM. Tapentadol, but not morphine, selectively inhibits disease-related thermal hyperalgesia in a mouse model of diabetic neuropathic pain. Neurosci Lett 2010;470:91-4

15 Steigerwald I, Muller M, Davies A, et al. Effectiveness and safety of tapentadol prolonged release for severe, chronic low back pain with or without a neuropathic pain component: results of an open-label, phase 3b study. Curr Med Res Opin 2012;28:911-36.

16 Michot B, Bourgoin S, Kayser $\mathrm{V}$, et al. Effects of tapentadol on mechanical hypersensitivity in rats with ligatures of the infraorbital nerve versus the sciatic nerve. Eur J Pain 2013;17:867-80.

17 Candiotti KA, Gitlin MC. Review of the effect of opioid-related side effects on the undertreatment of moderate to severe chronic non-cancer pain: tapentadol, a step toward a solution? Curr Med Res Opin 2010;26:1677-84. 
Copyright 2014 BMJ Publishing Group. All rights reserved. For permission to reuse any of this content visit http://group.bmj.com/group/rights-licensing/permissions.

BMJ Case Report Fellows may re-use this article for personal use and teaching without any further permission.

Become a Fellow of BMJ Case Reports today and you can:

- Submit as many cases as you like

- Enjoy fast sympathetic peer review and rapid publication of accepted articles

- Access all the published articles

- Re-use any of the published material for personal use and teaching without further permission

For information on Institutional Fellowships contact consortiasales@bmjgroup.com

Visit casereports.bmj.com for more articles like this and to become a Fellow 